\title{
Nasopharyngeal Paraganglioma
}

National Cancer Institute

\section{Source}

National Cancer Institute. Nasopharyngeal Paraganglioma. NCI Thesaurus. Code C48316.

A benign or malignant extra-adrenal paragang lioma arising from the nasopharynx and nose. Epistaxis or nasal obstruction are common presenting symptoms. 